\title{
Methods for monitoring tidal flushing in large animal burrows in tropical mangrove swamps
}

\author{
Suzanne E. Hollins ${ }^{\text {a,b,*, }}$, Scott F. Heron ${ }^{\text {a }}$, Peter V. Ridd ${ }^{\text {a }}$ \\ ${ }^{a}$ Marine Geophysical Laboratory, Department of Physics, School of Engineering and Physical Sciences, James Cook University, Townsville, Qld 4811, Australia \\ ${ }^{\mathrm{b}}$ Australian Nuclear Science and Technology Organisation, PMB1 Menai, NSW 2233, Australia
}

\section{A R T I C L E I N F O}

\section{Article history:}

Received 11 June 2008

Accepted 6 March 2009

Available online 14 March 2009

\section{Keywords:}

oxygen consumption

mangrove swamps

burrows

tidal flushing

Australia

Queensland

\begin{abstract}
A B S T R A C T
The typically anaerobic nature of mangrove sediments provides significant challenges to the mangrove trees and biota inhabiting them. The burrowing activities and flow of water through the numerous and complex animal burrows perforating the sediments of mangroves have a major influence on the biogeochemistry of the sediments and are important to the enhancement of nutrient and oxygen exchange. Two new methods are presented for monitoring the tidal flushing of Sesarma messa and Alpheus cf macklay burrows in a Rhizophora stylosa mangrove forest - by measuring oxygen content of burrow water and by determining the change in fluorescence of a dye tracer through tidal inundation. A case study using the first of these showed oxygen consumption rates at the burrow wall deep within the burrow were found to be between 210 and $460 \mu \mathrm{mol} \mathrm{O} \mathrm{O}^{-2} \mathrm{~h}^{-1}$. The influx of oxygen during a flood tide was found to be significant and indicated that approximately $40 \%$ of the burrow water is flushed during a single tidal event. However, the high consumption rate of oxygen within the burrow resulted in the oxygen concentration remaining at or below one-third of the oxygen content of the flooding tidal water. A test application of the second method, using rhodamine dye as a tracer, indicated that the exchange of water between the burrow and the flooding tide was found to be in the order of 30\% of the burrow volume. These new techniques provide a means to further study the nutrient exchange within these burrow systems and verify the initial findings that several tidal inundations are necessary to completely flush the burrows.
\end{abstract}

(c) 2009 Elsevier Ltd. All rights reserved.

\section{Introduction}

Mangroves grow in sediment that is commonly anaerobic in nature. This lack of oxygen stems from a high microbial oxygen demand (Golley et al., 1962) and a slow rate of diffusion in the highly impermeable and predominantly clay structure of many mangrove sediments. The anoxic conditions provide significant challenges to the mangrove trees. Mangroves must rely on transport of gas internally to satisfy their oxygen requirements (Scholander et al., 1955; Clough, 1992). The importance of pneumatophores and stilt roots in aeration during regular flooding was demonstrated by Scholander et al. (1955) and further investigated by Skelton and Allaway (1996). The rate of oxygen supply to the underground roots has often been found to exceed the respiration

\footnotetext{
* Corresponding author at: Suzanne E. Hollins, Australian Nuclear Science and Technology Organisation, Institute for Environmental Research, New Illawarra Road, PMB1 Menai, NSW 2233, Australia.

E-mail address: suzanne.hollins@ansto.gov.au (S.E. Hollins).
}

needs, resulting in diffusion of the excess oxygen into the surrounding sediment and the production of an oxidised rhizosphere (Thibodeau and Nickerson, 1986). The size of this oxidised rhizosphere tends to be smaller in highly reduced (anoxic) sediments than in moderately reduced sediments because of the high oxygen demand. The significance of the oxidised rhizosphere to nutrient availability has been well documented. The oxidised zone around the roots can exclude the numerous phytotoxins that are common in reduced sediments (Thibodeau and Nickerson, 1986) as well as increasing or decreasing the availability of a number of essential elements (Kristensen and Alongi, 2006; Mchenga and Tsuchiya, 2008). Further proof of this oxidised rhizosphere has been demonstrated through measurement of higher redox potentials and lower sulphide concentrations in the sediments around the prop roots of Rhizophora mangle and cable roots of Avicennia germinans which indicates a leakage of oxygen from the mangrove roots (McKee et al., 1988).

The low oxygen content and high microbial oxygen demand in mangrove sediments also provide challenges to the animals inhabiting the swamps. Crabs have had to develop numerous 
physiological adaptations such as aerial respiration in order to survive the difficult conditions (Jones, 1984). The burrowing and feeding of crabs and other benthic macrofauna are known to increase the topographic complexity; drainage and geochemistry of the sediment; and the rate of decomposition of plant litter within the sediment, as well as influencing the abundance and distribution of meiofauna (Montague, 1982; Bertness, 1985; Warren and Underwood, 1986; Boudreau and Marinelli, 1994; Aller and Aller, 1998; Koretsky et al., 2002; Kristensen, 2008). The burrows of fiddler crabs in salt marshes and Avicennia marina mangroves have been reported by numerous authors (Teal, 1959; Andersen and Kristensen, 1988) to have walls that are aerobic in nature, similar to the surface sediments.

The existence of this surplus of oxygen suggests a considerable input of oxygen from tidal inundation. The flow of water through the numerous animal burrows perforating the sediments of salt marshes and mangroves, and its potential enhancement of nutrient and oxygen exchange, has been well documented. Ridd (1996) proposed that $0.3-3 \%$ of the tidal water entering a mangrove swamp circulated through the animal burrows. Stieglitz et al. (2000a,b) replaced water from Crustacean burrows in a tropical mangrove swamp with a sugar solution with the same density as the tidal water and monitored the change in conductivity as the saline tidal water entered the burrow. From this they suggest that burrows were completely flushed within $1 \mathrm{~h}$ of tidal inundation. Heron and Ridd (2008) used computational models of the density effects during tidal inundation to determine that significant flushing of a burrow occurs during a single tidal event and that there is a depth limit to which tidal flushing occurs. They supported this finding using measurements of burrow water salinity through a tidal cycle. The rapid flushing of burrows with oxygen-rich tidal waters indicates a possibility of high oxygen levels within the burrow water itself and within the surrounding sediment, at least until microbial consumption acts to deplete oxygen levels.

This work presents two techniques for monitoring tidal flushing of Sesarma messa and Alpheus of macklay burrows in a Rhizophora stylosa mangrove forest. The first methodology monitors oxygen levels within the burrows during spring tides to determine the nontidal variation in oxygen content and the infiltration by oxygen-rich surface water into burrows, respectively. The second technique involves adding a fluorescent dye tracer to the burrow water and observing the decline in fluorescence through subsequent tidal inundations due to replacement of the burrow water. We seek to develop methods that can resolve the conflicting reports of the efficiency of tidal flushing as a mechanism for the exchange between surface and burrow waters and, therefore, the exchange of nutrients and toxins.

\section{Materials and methods}

Existing methods of oxygen monitoring in animal burrows have focussed on shallow burrow structures (Nielsen et al., 2004), where access to the burrows and surrounding sediment is relatively easy compared with the complexity and size of burrow structures studied here. As such, the technologies utilised for shallow burrows are limited in their application for this study. All measurements were made in burrows amongst the roots of a predominantly Rhizophora stylosa mangrove forest at Gordon's Creek, near Townsville, North Queensland, Australia. While a number of other species occupy the area in lesser numbers, the primary inhabitants of these burrows are Sesarma messa and Alpheus cf macklay (Stieglitz et al., $2000 \mathrm{~b}$ ) and these appear to co-habit the burrows. There is no evidence in literature that suggests either significant transport of oxygen by the animals into the burrows or of significant oxygen consumption by the animals. The openings to the burrows densely perforate the area, with ca. 15 openings per square metre the average number for this forest (Stieglitz et al., 2000b). The burrow structures are highly complex with multiple loops interwoven within a single connected burrow system and within other independent burrows. In general, burrow openings span a surface sediment area of $0.5-1.5 \mathrm{~m}^{2}$ and burrows are known to penetrate $1.3 \mathrm{~m}$ into the substrate with a typical burrow volume of around $65 \mathrm{l}$. The area is flooded by semi-diurnal tides ca. 15 days each month, when the tidal height exceeds about $3.0 \mathrm{~m}$ AHD (Australian Height Datum).

\subsection{Locating burrows and in situ sampling of burrow water}

The location of a suitable burrow was determined using an electrical conductivity probe that works on a concept similar to a half-Wenner array of electrodes commonly used in many geophysical applications. The probe consists of two titanium ring electrodes mounted on a fibreglass rod (Fig. 1). A $4 \mathrm{kHz}$ alternating current is driven through the current electrodes and the resulting potential measured with the receiver electrodes. The ratio of the current to the potential is then proportional to the electrical conductivity of the material around the electrodes. More detailed descriptions of the design principles of the electrical conductivity sensor and its use can be found in Hollins et al. (2000).

When the probe is inserted into the mangrove sediment and the electrodes pass from sediment into a water-filled burrow, the conductivity reading usually rises. The magnitude of this rise is dependent upon (a) the salinity of the burrow water in comparison to the salinity of pore water in the surrounding sediment, and (b) the porosity of the sediment. If the burrow water and pore water are of equal salinity, the conductivity reading will rise by a factor of approximately 2-3 as the sensor passes from sediment to burrow. Where a burrow is void of water, the conductivity drops markedly as the sensor passes from sediment to air. (For further description see Heron et al., 2002.)

The burrow diameter was determined by continuing to slowly push the conductivity probe further into the sediment until the conductivity readings fell again. The depth and position of the burrow centre were marked and the conductivity sensor was

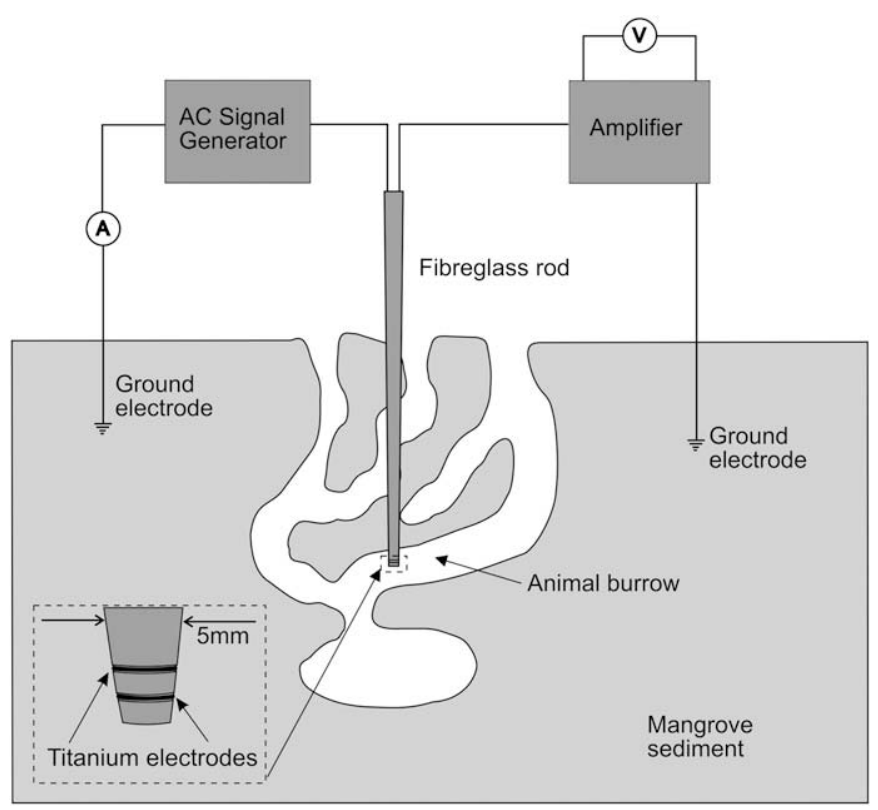

Fig. 1. Illustration of the electrical conductivity probe and set-up used to locate anima burrows in mangrove sediments. 
carefully removed. A rigid pipe, of similar diameter to the conductivity probe, was used for water sampling. The pipe was inserted in place of the conductivity sensor so that the tip of the pipe was in the centre of the burrow. Two lengths of PVC tubing extend down the inside of the pipe and exit on opposite sides of the pipe tip (Fig. 2). These two tubes provided a means of extracting water for oxygen concentration measurement and returning the water to the burrow.

A peristaltic pump continuously extracted water samples from the burrow for measurement of dissolved oxygen concentration using an amperometric Clark Electrode (TPS model WP-82). The water flow rate from the burrow through the inlet tube and into the chamber in which the oxygen sensor was housed was $50 \mathrm{ml} / \mathrm{min}$ (Fig. 2), thereby maintaining laminar flow for the system $(\mathrm{Re}=200)$. Measurements of dissolved oxygen concentration and temperature were taken regularly every 1-15 min over a period of $24 \mathrm{~h}$. The water then passed through the outlet tube and back into the burrow so that the system was disturbed as little as possible. The total volume of this external measuring system was approximately $200 \mathrm{ml}$, accounting for ca. $0.3 \%$ of the burrow volume. The measuring system was designed to be closed; i.e., no oxygen flux would occur during the transport of water from burrow to sensor and back to burrow. The oxygen sensor was calibrated before and after measurements using an oxygen free solution and an air calibration, as per instrument instructions.

\subsection{Oxygen consumption rates in a burrow}

For the measurements of the change in oxygen concentration in the burrows, i.e., oxygen consumption, the burrows were first emptied of the anoxic water contained in them. This was accomplished by locating a deep section of the burrow system $(0.5-1.0 \mathrm{~m}$ below the surface) with the conductivity sensor. A water-sampling pipe was inserted and all the water was extracted using an electric pump. Locating a deep section connected with the surface openings

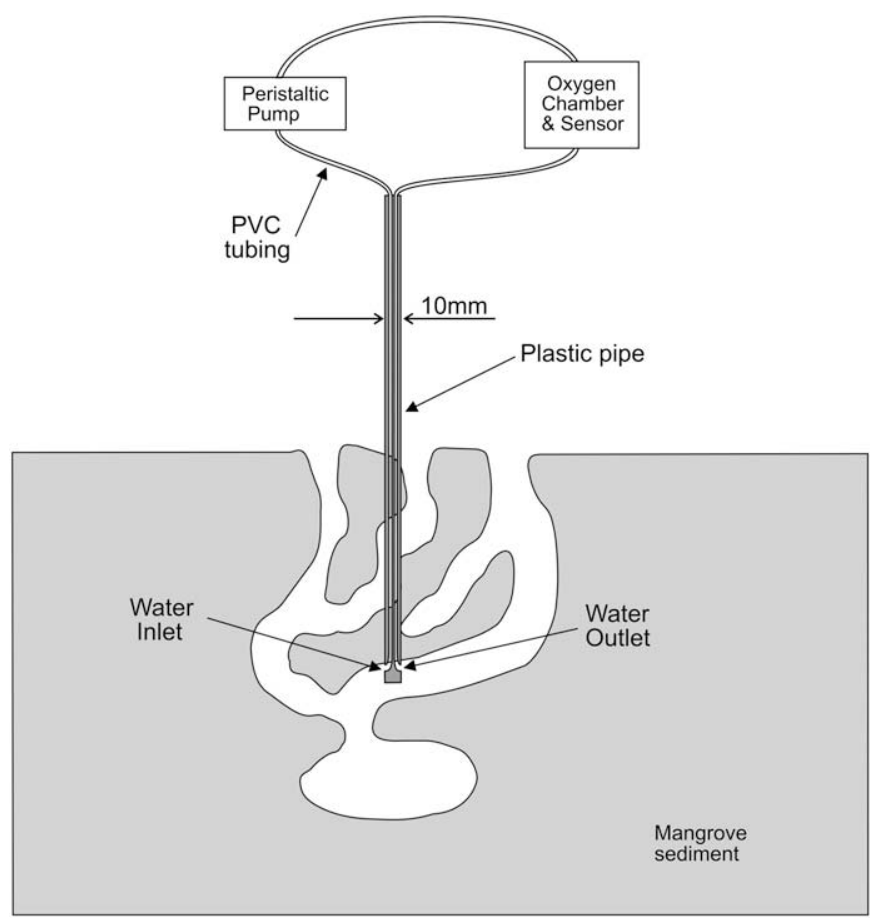

Fig. 2. Equipment used to measure dissolved oxygen concentration in the burrows of Sesarma messa and Alpheus cf macklay in a Rhizophora stylosa mangrove forest. of a particular burrow system was often difficult due to the manner in which adjacent burrow systems were generally intertwined.

When all the water had been removed from the burrow, highly oxygenated water from nearby Gordon's Creek was pumped into the burrow. The measurement system shown in Fig. 2 was then quickly set-up with the pump attached to the water-sampling pipe in the upper section. The peristaltic pump was allowed to operate for $20 \mathrm{~min}$ before oxygen readings were taken so that the external measuring system was flushed a number of times. This ensured that there were no air bubbles in the system and that the water was well mixed before measurements began. The concentration of oxygen in the burrow water was recorded at regular intervals, in the range 1$15 \mathrm{~min}$, over a period up to $24 \mathrm{~h}$. The entire process of emptying the burrow, refilling with oxygenated water and measuring the consumption rate of oxygen was repeated daily for a week. Each sensor's membrane was replaced every $24 \mathrm{~h}$ to prevent spoiling by the anoxic conditions in which they were continually taking measurements.

Microbial consumption of oxygen may occur at both the burrow wall and within the burrow water. In order to independently estimate the magnitude of the burrow volume consumption rate, a further experiment was undertaken in which oxygenated water from Gordon's Creek was stored in a sealed, black plastic container and then monitored for oxygen concentration over several days.

\subsection{Oxygen concentration changes in burrow water during a tidal inundation}

The set-up shown in Fig. 2 was used to make measurements of the oxygen concentration in the burrow water during inundation of the mangrove swamps by spring high tides. Measurements were made every $15 \mathrm{~min}$ throughout $12-24 \mathrm{~h}$ periods during which a daily spring tidal flooding occurred.

\subsection{Measuring the tidal flushing of a burrow using rhodamine}

The volume of water flushed out of the burrow by a tidal inundation was also measured using rhodamine dye as a tracer. A suitable burrow was located using the method previously described and the burrow water was extracted using a process similar to that described in Section 2.1. However, in this instance the extracted water was stored in a temporary container and Rhodamine dye was added. The water was cycled through the burrow and back into the storage container a number of times to ensure proper mixing of the rhodamine dye, and was then returned to the burrow. Samples of water were extracted from the upper and lower sections of two burrow systems at various times before, during and after tidal inundation, and the rhodamine concentration was measured using a fluorometer. Measurements were repeated over a period of five days during which the field site was inundated four times by high tides.

\section{Results}

\subsection{Oxygen consumption rates in a burrow}

Fig. 3 shows the decay rate by microbial consumption in a burrow from which the existing oxygen depleted water has been removed and replaced by water with much higher oxygen content from the nearby tidal creek. Oxygen concentration follows a distinctive exponential decrease during a typical 24-h period when there was no tidal inundation of the mangrove forest (Fig. 3a). When a high tide inundated the forest floor about $8 \mathrm{~h}$ into the measurement period, a small temporary increase in oxygen concentration occurred subsequently (Fig. $3 \mathrm{~b}$ ). The oxygen content 


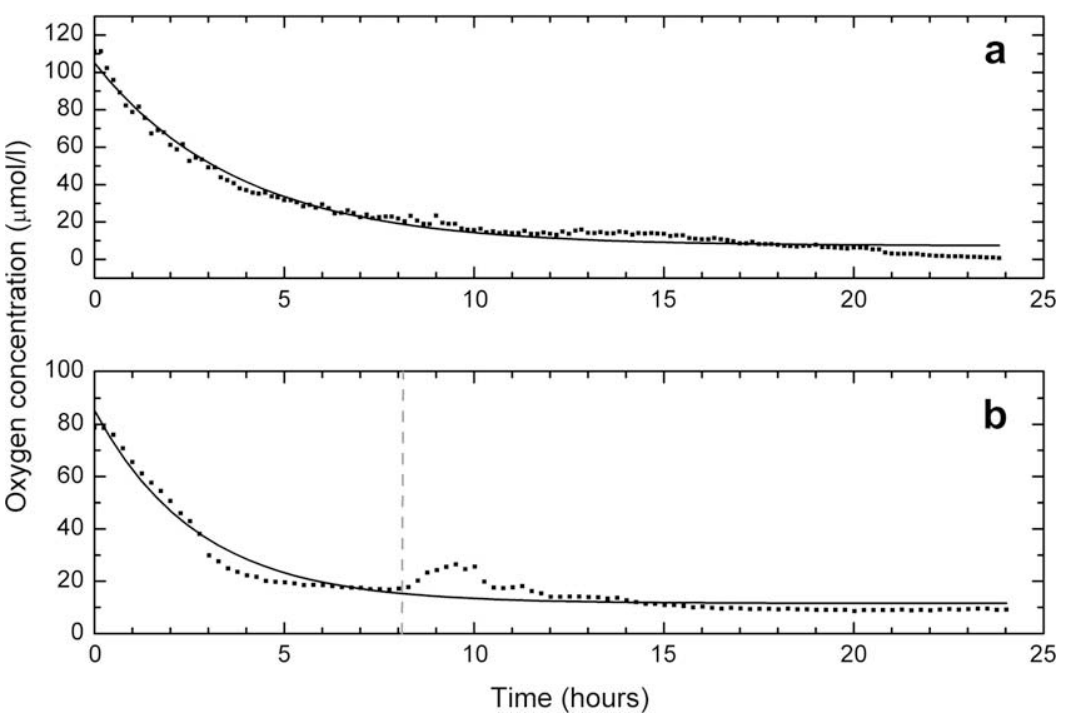

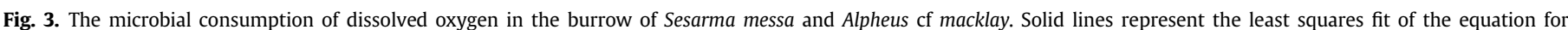

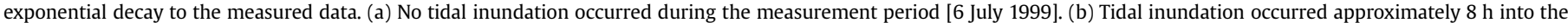
measurement period [ 1 July 1999].

within the isolated plastic container was found to be near-constant throughout the multi-day monitoring, indicating little consumption within the water itself.

\subsection{Oxygen concentration changes in a burrow during a tidal inundation}

A typical example of oxygen readings in a burrow, through a 15$h$ period centred on a single high tide event $(3.5 \mathrm{~m})$ inundating the mangrove forest floor, is shown in Fig. 4. Oxygen concentration increases rapidly during tidal inundation. The subsequent decline in oxygen concentration occurs faster than exponential decay (i.e., microbial uptake) alone, suggesting that mixing of oxygenated waters with unflushed burrow water is also occurring. The oxygen concentration remains close to zero before inundation and despite the flooding of the forest floor, the concentration in the burrow water rarely rises above $30 \mu \mathrm{mol} / \mathrm{l}$. Even when the inundating flood water measured at more than $65 \%$ of oxygen saturation $(138 \mu \mathrm{mol} / \mathrm{l})$, the oxygen content in the burrow water of Sesarma messa and Alpheus of macklay was never found to increase above $25 \%$ of saturation $(53 \mu \mathrm{mol} / \mathrm{l})$.

\subsection{Measurement of the tidal flushing of a burrow using rhodamine}

Table 1 shows the fluorescence readings in the burrow water of Sesarma messa and Alpheus cf macklay before, during and after inundation by four high tides. The measurements show some variation in the amount of water exchanged between the burrow and the tidal water during each tidal inundation. By considering the percentage reduction in fluorescence measured at each position (top and bottom) in both burrows through each of the tidal inundations (refer Table 1 for inundation times), there is an average volume exchange of $30 \%$ between the burrow and tidal water per inundation. As such, through four tidal inundations the rhodamine concentrations were reduced by approximately $80 \%$.

\section{Discussion}

The decrease in the microbial consumption of oxygen in the burrow water (Fig. 3) is described by the exponential decay equation

$C(t)=B C_{i} \mathrm{e}^{-k t}+D$,

where $C$ is the oxygen concentration of the burrow water, $C_{i}$ is the initial oxygen concentration of the burrow water and $B, k$ and $D$ are constants. These constants were obtained with a least squares fit of the exponential decay function to the data series, as shown in Fig. 3. The decay constant $k$ was found to range in different experiments from $0.25 \mathrm{~h}^{-1}$ to $0.78 \mathrm{~h}^{-1}$, corresponding with values of $B$ in the range 0.95 and 0.68 , respectively. The residual oxygen concentration, $D$, varied between 2.2 and $20.0 \mu \mathrm{mol} / 1$ across the burrows measured; however, these values were often influenced by tidal influx of oxygen and the final measured oxygen concentration for

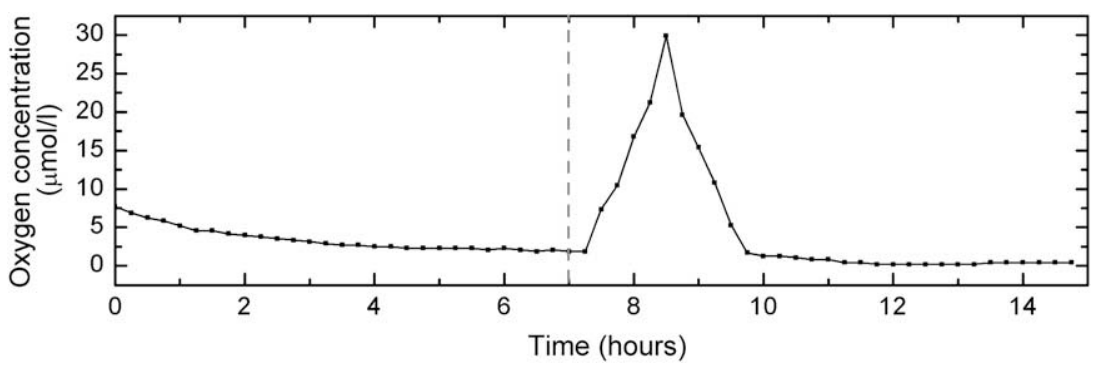

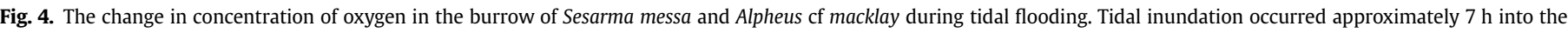
measurement period [15 March 1999]. 
Table 1

Fluorescence readings in the burrow water of Sesarma messa and Alpheus cf macklay (tidal inundation at 1918,6/9/99; 1953,7/9/99; 2027,8/9/99: 2100,9/9/99).

\begin{tabular}{|c|c|c|c|c|c|}
\hline & & \multicolumn{2}{|l|}{ Burrow 1} & \multicolumn{2}{|l|}{ Burrow 2} \\
\hline & & \multicolumn{2}{|c|}{ Fluorescence reading } & \multicolumn{2}{|c|}{ Fluorescence reading } \\
\hline & & \multicolumn{2}{|c|}{ (Fraction of value at 1830 on 6/9/99) } & \multicolumn{2}{|c|}{ (Fraction of value at 1830 on 6/9/99) } \\
\hline Date & Time & Top of Burrow & Bottom of Burrow & Top of Burrow & Bottom of Burrow \\
\hline $6 / 9 / 99$ & 1830 & 1.00 & 1.00 & 1.00 & 1.00 \\
\hline 6/9/99 & 2030 & 0.73 & 0.85 & 0.77 & 0.89 \\
\hline $7 / 9 / 99$ & 1400 & 0.27 & 0.30 & 0.71 & 0.19 \\
\hline $8 / 9 / 99$ & 1930 & 0.15 & 0.27 & 0.41 & 0.11 \\
\hline $8 / 9 / 99$ & 2200 & 0.16 & 0.18 & 0.24 & 0.07 \\
\hline $10 / 9 / 99$ & 1100 & 0.07 & 0.12 & 0.20 & 0.10 \\
\hline
\end{tabular}

each burrow tested was below this residual level. The wide range in decay coefficients may be due to different wall constituents, with varying rates of oxygen consumption, in the burrows sampled. It may also be related to the movement of resident animals through the burrow (Heron and Ridd, 2008) and/or the regularity of tidal inundation.

Note that an oxygen concentration time dependency as described by equation (1) implies that oxygen is consumed at a rate proportional to concentration:

$\frac{\mathrm{d} C(t)}{\mathrm{d} t}=-k C_{i} B \mathrm{e}^{-k t}$

Applying conservation of mass for oxygen, the scale relation relating the time rate of change of oxygen concentration of the burrow water to the volume and wall area of the burrow is:

$\frac{\Delta C}{\Delta t}=-\frac{A}{V} Q_{A}-Q_{V}$

where $Q_{A}$ is the burrow surface oxygen consumption rate (units: mass of $\mathrm{O}_{2}$ /area/time), $Q_{V}$ is the burrow volume oxygen consumption rate (units: mass of $\mathrm{O}_{2} / \mathrm{vol} /$ time), and $A$ and $V$ are the wall area and the volume of the burrow respectively. The total burrow consumption rate combines the microbial consumption rate of the burrow wall, $Q_{A}$, and the consumption rate in the burrow water, $Q_{V}$. Based on the constant nature of the oxygen concentration in the sealed container, the volume consumption rate for the water introduced to the burrow was negligible and so equation (3) can be simplified as:

$\frac{\Delta C}{\Delta t}=-\frac{A}{V} Q_{A}$

The burrow wall oxygen consumption rate can be estimated using equation (4) and the values of the typical burrow wall area and volume measured by Stieglitz et al. (2000b). The average wall area, $A$ and the average volume, $V$ of the burrow were taken to be $4.0 \mathrm{~m}^{2}$ and 651 respectively. Assuming an initial concentration of $53 \mu \mathrm{mol} / \mathrm{l}$ (the highest measured oxygen concentration in the burrows) and using the range of values for the constants $B$ and $k$ calculated above, the maximum consumption rate of the burrow wall can be estimated to be in the range $210-460 \mu \mathrm{mol} \mathrm{O} \mathrm{m}^{-2} \mathrm{~h}^{-1}$ Previous estimates of oxygen consumption at burrow walls for less than $10 \mathrm{~cm}$ depth polychaete burrows were in the range 750 $2500 \mu \mathrm{mol} \mathrm{O} \mathrm{m}^{-2} \mathrm{~h}^{-1}$ (Nielsen et al., 2004), faster than the rates observed here. However, this is believed to be the first time such a consumption rate has been measured deep within complex burrow structures. Surface sediment respiration rates in tropical mangrove forests have been measured in the range 197-1645 $\mu \mathrm{mol}$ $\mathrm{O}_{2} \mathrm{~m}^{-2} \mathrm{~h}^{-1}$ (Alongi, 1994), which is consistent with the values observed for the sediment in the burrow walls. For a typical burrow, of wall area $4.0 \mathrm{~m}^{2}$, this suggests that the oxygen consumption rate at tidal inundation is $830-1820 \mu \mathrm{mol} \mathrm{h}^{-1}$.

From Fig. 4, the oxygen concentration of the burrow water remains below $31 \mu \mathrm{mol} / \mathrm{l}$ even after being inundated with tidal water with oxygen concentrations of up to $160 \mu \mathrm{mol} / \mathrm{l}$. In order for oxygen concentration within the burrow water to increase, we require the rate of tidal oxygen input to be greater than the burrow consumption rate.

The measurements of the tidal flushing rate of the burrow (Table 1) show, on average, a 30\% exchange between the burrow and tidal water. Here we employ observations that the average oxygen content of the tidal water is $140 \mu \mathrm{mol} / \mathrm{l}$ ( $65 \%$ of saturation) and the tidal flushing occurs over an average of $4 \mathrm{~h}$. Based on this, the average rate of tidal oxygen input to a $65 \mathrm{l}$ burrow is $680 \mu \mathrm{mol}$ of $\mathrm{O}_{2}$ per hour. The measured consumption rate of oxygen in the burrow, $830-1820 \mu \mathrm{mol}$ of $\mathrm{O}_{2}$ per hour, is generally higher than the average oxygen input. With the consumption rate up to three times greater than the average tidal oxygen input, the oxygen concentration in the burrow would never be expected to equal the concentration caused by the influx of oxygen during that partial flushing of inundation. Assuming the oxygen input during inundation $(30 \%$ exchange of $140 \mu \mathrm{mol} / \mathrm{l}$ water) is mixed throughout the burrow (Heron and Ridd, 2008), then a typical maximum burrow oxygen concentration is approximately $40 \mu \mathrm{mol} / \mathrm{l}$. This is consistent with observations of low oxygen concentrations in the burrow water during and immediately after inundation of the swamp with spring high tides.

The observed exchange of water between the burrows and the inundating tidal water is somewhat at variance with previous measurements of the flushing rate. The fluorescence measurements indicate an average of $30 \%$ flushing during an inundation and thus show a need for at least three inundations before the burrow is completely flushed. Stieglitz et al. (2000b) claim a complete flushing of a 68-1 burrow, in the same field site, within $1 \mathrm{~h}$ of a single tidal inundation. Heron and Ridd (2008) report a flushing depth limit of $30-35 \mathrm{~cm}$, corresponding to approximately $40-50 \%$ of burrow volume flushed and thus suggesting 2-3 tidal events to flush the burrow.

The measurements of oxygen concentration in the burrows also provide an indication of the flushing rates of the burrows by using the oxygen as a tracer. Fig. 4 shows the change in oxygen concentration through a tidal flooding event (at a time of $8 \mathrm{~h}$ ). Oxygen concentration changes from 3 to $31 \mu \mathrm{mol} / \mathrm{l}$ over a period of about $1.2 \mathrm{~h}$. The consumption of oxygen in this time is, on average, $1325 \mu \mathrm{mol} \mathrm{h}^{-1}$ so that $1590 \mu \mathrm{mol}$ of oxygen would be consumed. A rise in the oxygen concentration of $28 \mu \mathrm{mol} / \mathrm{l}(1820 \mu \mathrm{mol}$ for a $65 \mathrm{l}$ burrow) would exceed this amount, thereby requiring $3410 \mu \mathrm{mol}$ of oxygen to be introduced to the burrow by the tide. The tidal input of oxygen is the product of the surface-water concentration ( $140 \mu \mathrm{mol} / \mathrm{l})$ by the number of litres of water exchanged, indicating 
an exchange of 241 of water between the tide and the burrow (37\% of the total volume of the burrow). This is in reasonable agreement with the flushing rate calculated by the fluorescence experiment and that reported by Heron and Ridd (2008).

The discrepancy with the flushing rates obtained by Stieglitz et al. (2000b) may be due to density effects. In order to determine the flushing rate, Stieglitz et al. (2000b) monitored changes in electrical conductivity of the burrow water during a tidal inundation. Burrow water was replaced with a sugar solution of low conductivity prior to a tidal flooding. In order to try and eliminate density effects on the flushing rate, the sugar solution was made so that the density of the "new" burrow water was equal to the surface-water density. However, in dry conditions such as existed during our measurement period, the burrow water was measured to have a salinity of $1 \mathrm{psu}$ greater than the surface tidal water and this acts to hinder the flushing of the burrows (Heron and Ridd, 2003).

\section{Conclusion}

Two methods are introduced to monitor the tidal flushing of animal burrows in mangrove swamps. The first of these considers the oxygen content of burrow water extracted from deep within the burrow through tidal inundation. The second adds a fluorescent dye tracer to the burrow water and measures the change in fluorescence of water samples during the tidal event. Test applications of these techniques indicated that the tidal flushing rate of the burrows was found to be around $30-40 \%$ of the burrow volume, in accord with Heron and Ridd (2008) but in variance with Stieglitz et al. (2000b) who observed complete flushing of the burrow within one tidal inundation. The findings here suggest that a series of tidal inundations is necessary to fully replace burrow water and, therefore, flush accumulated toxins from the burrow system. The further application of these techniques for complex burrow structures will resolve the question of the efficiency of the tidal flushing mechanism. This question is significant in understanding the transfer of nutrients and toxins between surface and ground water through animal burrows found in sediment whose impermeability severely hinders other mechanisms of exchange.

\section{References}

Aller, R.C., Aller, J.Y., 1998. The effect of biogenic irrigation intensity and solute exchange on diagenetic reaction rates in marine sediments. Journal of Marine Research 56, 905-936.

Alongi, D.M., 1994. Zonation and seasonality of benthic primary production and community respiration in tropical mangrove forests. Oecologia 98, 320-327.

Andersen, F.O., Kristensen, E., 1988. Oxygen microgradients in the rhizosphere of the mangrove Avicennia marina. Marine Ecology Progress Series 44, 201-204.

Bertness, M.D., 1985. Fiddler crab regulation of Spartina alterniflora production on a New England salt marsh. Ecology 66, 1042-1055.
Boudreau, B.P., Marinelli, R.L., 1994. A modelling study of discontinuous irrigation. Journal of Marine Research 52, 947-968.

Clough, B.F., 1992. Primary productivity and growth of mangrove forests. In: Robertson, A.I., Alongi, D.M. (Eds.), Coastal \& Estuarine Studies 41: Tropical Mangrove Ecosystems. A.G.U., Washington D.C.

Golley, F., Odum, H.T., Wilson, R.F., 1962. The structure and metabolism of a Puerto Rican red mangrove forest in May. Ecology 43, 9-19.

Heron, S.F., Hollins, S.E., Ridd, P.V., 2002. The use of conductivity probes to locate animal burrows in mangrove swamps. IEEE Oceans, Biloxi USA, 29-31 Oct 2002, CDROM, 1071-1077.

Heron, S.F., Ridd, P.V., 2003. The effect of water density variations on the tida flushing of animal burrows. Estuarine, Coastal and Shelf Science 58, 137-145.

Heron, S.F., Ridd, P.V., 2008. The tidal flushing of multiple-loop animal burrows. Estuarine, Coastal and Shelf Science 78, 135-144.

Hollins, S.E., Ridd, P.V., Read, W.W., 2000. Measurement of the diffusion coefficient for salt in salt flat and mangrove soils. Wetlands Ecology and Management 8 257-262.

Jones, D.A., 1984. Crabs of the mangal ecosystem. In: Por, F.D., Dor, I. (Eds.) Hydrobiology of the Mangal. Dr W. Junk Publishers, The Hague.

Koretsky, C.M., Meile, C., Van Cappellen, P., 2002. Quantifying bioirrigation using ecological parameters: a stochastic approach. Geochemical Transactions 3 , 17-30.

Kristensen, E., 2008. Mangrove crabs as ecosystem engineers; with emphasis on sediment processes. Journal of Sea Research 59, 30-43.

Kristensen, E., Alongi, D.M., 2006. Control by fiddler crabs (Uca vocans) and plant roots (Avicennia marina) on carbon, iron and sulphur biogeochemistry in mangrove sediments. Limnology and Oceanography 51, 1557-1571.

Mchenga, I.S.S., Tsuchiya, M., 2008. Nutrient dynamics in mangrove crab burrow sediments subjected to anthropogenic input. Journal of Sea Research 59, 103-113.

McKee, K.L., Mendelssohn, I.A., Hester, M.W., 1988. Reexamination of pore water sulfide concentrations and redox potentials near the aerial roots of Rhizophora mangle and Avicennia germinans. American Journal of Botany 75, 1352-1359.

Montague, C.L., 1982. The influence of fiddler crab burrows and burrowing on metabolic processes in salt marsh sediments. In: Kennedy, V.S. (Ed.), Estuarine Comparisons. Academic Press, New York.

Nielsen, O.I., Gribsholt, B., Kristensen, E., Revsbech, N.P., 2004. Microscale distribution of oxygen and nitrate in sediment inhabited by Nereis diversicolor spatial patterns and estimated reaction rates. Aquatic Microbial Ecology 34, 23-32.

Ridd, P.V., 1996. Flow through animal burrows in mangrove creeks. Estuarine Coastal and Shelf Science 43, 617-625.

Scholander, P.F., van Dam, L., Scholander, S.I., 1955. Gas exchange in the roots of mangroves. American Journal of Botany 42, 92-98.

Skelton, N.J., Allaway, W.G., 1996. Oxygen and pressure changes measured in situ during flooding in roots of the grey mangrove Avicennia marina (Forssk.) Vierh. Aquatic Botany 54, 165-175.

Stieglitz, T., Ridd, P.V., Hollins, S., 2000a. A small sensor for detecting anima burrows and monitoring burrow water conductivity. Wetlands Ecology and Management 8, 1-7.

Stieglitz, T., Ridd, P., Müller, P., 2000b. Passive irrigation and functional morphology of crustacean burrows in a tropical mangrove swamp. Hydrobiologia 421, 69-76.

Teal, J.M., 1959. Respiration of crabs in Georgia salt marsh and its relation to their ecology. Physiological Zoology 32, 1-14.

Thibodeau, F.R., Nickerson, N.H., 1986. Differential oxidation of mangrove substrate by Avicennia germinans and Avicennia mangle. American Journal of Botany 73 , 512-516.

Warren, J.H., Underwood, A.J., 1986. Effects of burrowing crabs on the topography of mangrove swamps in New South Wales. Journal of Experimental Marine Biology and Ecology 102, 223-235. 